\title{
Inhibition of p300 lysine acetyltransferase activity by luteolin reduces tumor growth in head and neck squamous cell carcinoma (HNSCC) xenograft mouse model
}

\author{
Ruthrotha B. Selvi ${ }^{1}$, Amrutha Swaminathan ${ }^{1}$, Snehajyoti Chatterjee ${ }^{1}$, Muthu \\ K. Shanmugam², Feng Li ${ }^{2}$, Gowsica B. Ramakrishnan ${ }^{1}$, Kodappully Sivaraman \\ Siveen $^{2}$, Arunachalam Chinnathambi ${ }^{3}$, M. Emam Zayed ${ }^{3}$, Sulaiman Ali Alharbi ${ }^{3}$, \\ Jeelan Basha ${ }^{1}$, Akshay Bhat ${ }^{1}$, Madavan Vasudevan ${ }^{4}$, Arunasalam Dharmarajan ${ }^{5}$, \\ Gautam Sethi ${ }^{2,3,5}$ and Tapas K. Kundu ${ }^{1}$ \\ ${ }^{1}$ Transcription and Disease Laboratory, Molecular Biology and Genetics Unit, Jawaharlal Nehru Centre for Advanced Scientific \\ Research, Jakkur P.O., Jakkur, Bangalore, India \\ 2 Department of Pharmacology, Yong Loo Lin School of Medicine, National University of Singapore, Singapore \\ ${ }^{3}$ Department of Botany and Microbiology, College of Science, King Saud University, Riyadh, Kingdom of Saudi Arabia \\ ${ }^{4}$ Bionivid Technology [P] Ltd, East of NGEF, Bangalore, India \\ ${ }^{5}$ School of Biomedical Sciences, CHIRI Biosciences Research Precinct, Curtin University, Bentley, Western Australia, Australia \\ Correspondence to: Tapas K. Kundu, email: tapas@jncasr.ac.in
}

Keywords: flavonoids, miRNA, gene expression, cancer

Received: May 22, $2015 \quad$ Accepted: October 14, $2015 \quad$ Published: October 26, 2015

This is an open-access article distributed under the terms of the Creative Commons Attribution License, which permits unrestricted use, distribution, and reproduction in any medium, provided the original author and source are credited.

\section{ABSTRACT}

Chromatin acetylation is attributed with distinct functional relevance with respect to gene expression in normal and diseased conditions thereby leading to a topical interest in the concept of epigenetic modulators and therapy. We report here the identification and characterization of the acetylation inhibitory potential of an important dietary flavonoid, luteolin. Luteolin was found to inhibit p300 acetyltransferase with competitive binding to the acetyl CoA binding site. Luteolin treatment in a xenografted tumor model of head and neck squamous cell carcinoma (HNSCC), led to a dramatic reduction in tumor growth within 4 weeks corresponding to a decrease in histone acetylation. Cells treated with luteolin exhibit cell cycle arrest and decreased cell migration. Luteolin treatment led to an alteration in gene expression and miRNA profile including up-regulation of p53 induced miR-195/215, let7C; potentially translating into a tumor suppressor function. It also led to downregulation of oncomiRNAs such as miR-135a, thereby reflecting global changes in the microRNA network. Furthermore, a direct correlation between the inhibition of histone acetylation and gene expression was established using chromatin immunoprecipitation on promoters of differentially expressed genes. A network of dysregulated genes and miRNAs was mapped along with the gene ontology categories, and the effects of luteolin were observed to be potentially at multiple levels: at the level of gene expression, miRNA expression and miRNA processing.

\section{INTRODUCTION}

Reversible histone acetylation has been now recognised as a key epigenetic modification for the regulation of gene expression. The enzymatic machinery involved in this process has also been shown to possess important regulatory roles in physiological and pathophysiological conditions and therefore viewed as attractive therapeutic target. Small molecule modulators of these enzymes have been identified and their therapeutic efficacies being tested both in pre-clinical and clinical studies. However, the existing inhibitors suffer from one or more of the following shortcomings of non-specific mode of action, decreased cell permeability or metabolic 
instability. Hence, there is an active search for better inhibitors from natural sources as well as for the synthesis of better molecules. Surprisingly, a vast majority of the inhibitors have been identified from the natural sources and based on these scaffolds, efficient molecules have been synthesized (reviewed in [1] and references thereof). The first natural and potent acetyltransferase inhibitor (KATi), anacardic acid was isolated from Cashew Nut Shell Liquid (CNSL) was found to be poorly permeable to cells. Garcinol, a polyisoprenylated benzophenone from the kokum fruit (Garcinia indica) also found later on as a potent KATi with a non-specific mode of action, was subsequently derivatized into LTK14, a p300 specific KATi with promising therapeutic potential [2]. One of the most important natural source derived KATi is CTK7A, a water soluble derivative of curcumin which exhibited tumour regression ability in oral cancer xenograft model system [3]. Although these natural source-derived and modified KATi and several other synthetic KATi such as lysyl CoA [4] and C646 [5] have shown tremendous potential in several preclinical studies, most of these are limited by their working concentrations or their apparent difficulties to be metabolized. All these shortcomings have resulted in an ongoing effort to identify better and efficient molecules with improved therapeutic index.

During one such screening process, we had earlier identified that the crude extract of pomegranate fruit rind had a potent p300 acetyltransferase inhibitory activity. The subsequent purification of this extract had led to the identification of another active component which incidentally was an inhibitor of arginine methyltransferase [6], which was later used as a tool to understand the role of PRMT4 in neural/glial differentiation [7]. However, to find the potential new inhibitor in the crude extract, we decided to assay with the known components of the crude extract. Incidentally, majority of them were flavonoids, an important dietary constituent found in several edible fruits and vegetables. Flavonoids have been attributed with antioxidant property, potential to slow ageing, protection against cardiac diseases, ability to lower the risk of diabetes, cancer, stroke and also neurodegenerative disorders like dementia, Alzheimers' and Parkinsons'[8-10]. A major contribution to most of these diseases is ROS and the flavonoids have been considered to have protective effect against ROS generation [11] Several efforts have been taken to identify the mechanism of action of these important dietary constituents and a few studies have reported their perturbations of the signalling pathways [12]. However, no studies have as yet reported any effect of the flavonoids on histone acetylation. Hence, we attempted to identify the possible mechanism of action of flavonoids in the context of epigenetic modifications with special emphasis on histone acetylation.

By employing systematic screening of the pomegranate skin tannins and flavonoids, we found that luteolin, but not the structurally related apigenin, is a potent, specific competitive inhibitor of p300 acetyltransferase activity with an IC50 of $7 \mu \mathrm{M}$. Luteolin could inhibit histone acetylation in cultured cells and also in in vivo xenograft mouse model, the growth of which was retarded upon luteolin treatment. Apart from the direct effect on histone acetylation in the protein coding gene promoters resulting in downregulation of important cytokines like IL6, luteolin treatment also led to a significant alteration in the expression of miRNAs. Alteration of miRNA expression levels regulates the protein coding genes post transcriptionally. Interestingly, the profile of the upregulated miRNAs clustered towards tumor suppression, with many miRNAs being known inducers of cell cyle arrest and negative regulators of cell migration. The miRNAs with downregulated expression were predominantly classified into the oncomiR category. DICER, a component of the miRNA processing machinery was also found to be differentially expressed, which can also contribute to changes in miRNA processing. Thus, the important dietary flavonoid, luteolin was found to be a p300 acetyltransferase inhibitor, with the ability to modulate gene expression, miRNA expression and potentially, miRNA processing, correlating to a tumour suppressor outcome, which was also reflected in HNSCC tumor xenograft model.

\section{RESULTS}

\section{Luteolin from PCE inhibits p300 KAT activity}

The Pomegranate crude extract (PCE) components (Figure 1A) were screened using p300 acetyltransferase and arginine methyltransferase (RMTase), CARM1 (Figure 1B). Our earlier study had shown that the crude extract had a strong inhibitory activity on these two classes of enzymes [2]. Of all the compounds, only ellagic acid was found to inhibit CARM1 (Figure 1B). However, most strikingly luteolin could almost completely inhibit the acetyltransferase activity of p300 very potently while all the other components were ineffective.

Luteolin is a dietary flavonoid, which possesses diverse important physiological effects on human cells. The flavonoids include flavonols, dihydroflavonols, flavones, isoflavones, flavanones, anthocyanins, and anthocyanidins. Significantly, of the different flavonoids, we screened for the major category of flavones (luteolin, apigenin, chrysin, pinostrobin), flavonols (galangin, kaempferol, quercetin, myricetin, rutin, silymarin) and flavanols (catechin, EGCG), only luteolin showed potential p300 (but not PCAF) KAT inhibition ability (Figure 1C). These compounds are characterised by polyhydroxy functional groups (Figure 1A). An earlier study from our group has shown that the -OH group is critical for the inhibition of KAT activity [13]. It is pertinent to 
point out here that even apigenin which structurally differs with luteolin only by one -OH group at 4'- position, could not affect the p300 or PCAF KAT activity (Figure 1C). Collectively, among all twelve flavonoids tested, only luteolin could inhibit the KAT activity of p300.

It was intriguing that luteolin could inhibit p300 whereas the structurally similar apigenin did not have any effect. To investigate whether the presence of an
$\mathbf{A}$
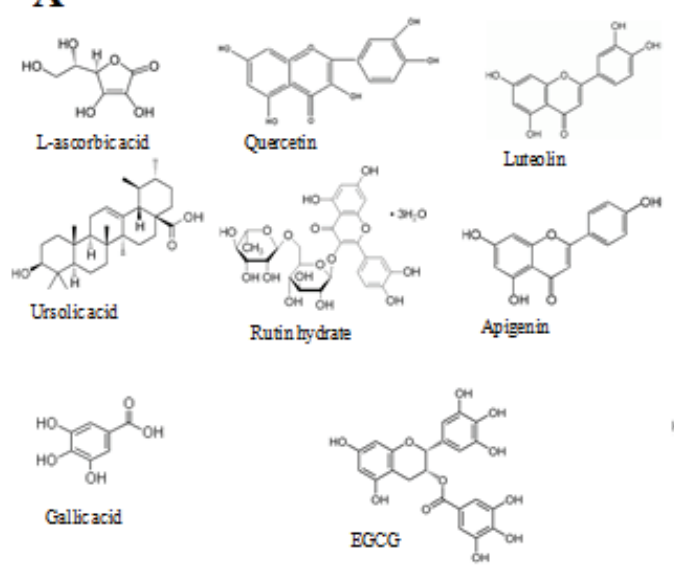

D
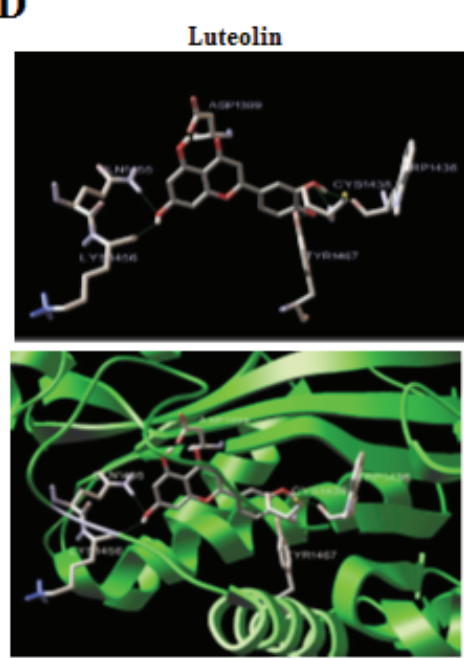

$\mathbf{E}$
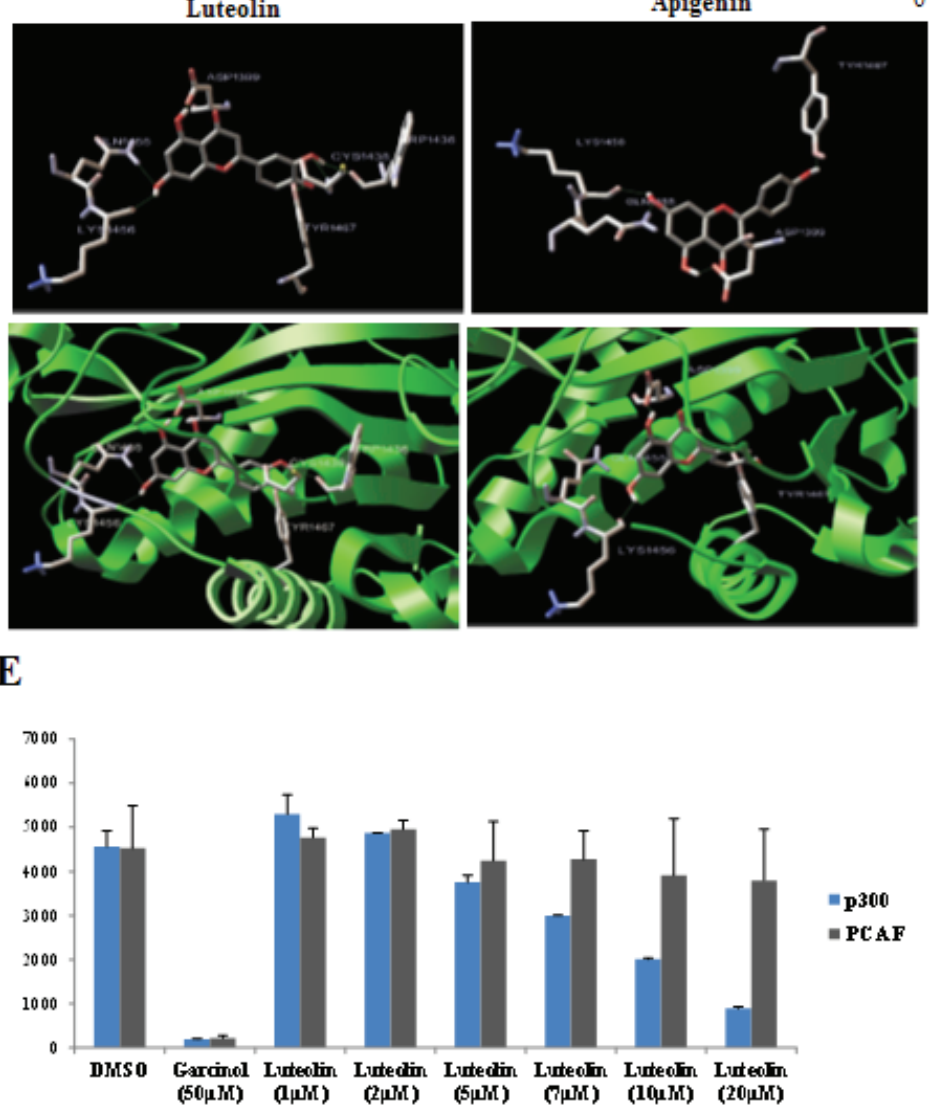

B
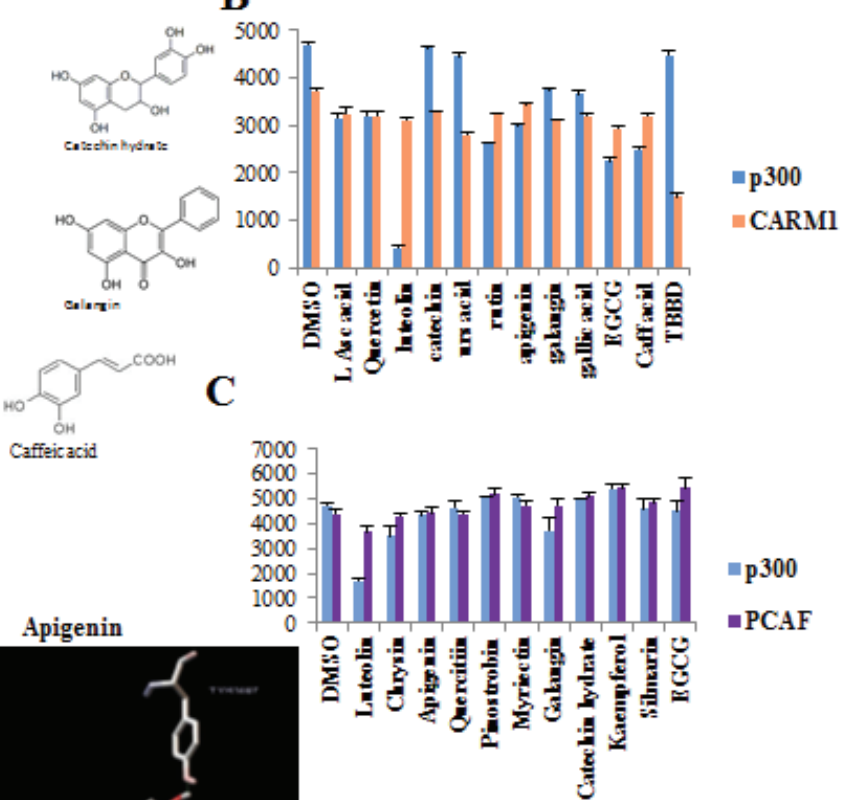

PCAF 
additional $-\mathrm{OH}$ group conferred luteolin with differential binding abilities; we performed a molecular simulation and docking study on p300 minimal HAT domain (Figure 1D). We identified that luteolin and apigenin had common binding sites on the acetyltransferase domain, of which the important one being Y1467-identified in the C646, p300 KAT inhibitor study [5]. However, the significant difference between luteolin and apigenin binding to the p300 HAT domain (HD) is with respect to two residues (W1436 and C1438). Luteolin exhibited binding to W1436 which is a critical residue on p300 HD. In agreement with this observation, point mutation of W1436 to alanine was found to abolish the KAT activity of the p300 HD in an earlier study [14]. Another unique residue for luteolin binding is $\mathrm{C} 1438$ which was identified as a part of the substrate binding loop L1 (Figure 1D). Interestingly, various cancers and Rubinstein Taybi syndrome is associated with mutations at C1438 [14]. The presence of an additional - $\mathrm{OH}$ group in luteolin led to the binding to two important residues on the p300 KAT domain which results in an apparent decrease in the inhibition constant by more than threefold as represented in supplementary table 1. On the other hand, the same analysis was also performed on PCAF acetyltransferase domain and although there were common binding sides, the observed $\mathrm{Ki}$ was too high which also correlated to the non-inhibitory pattern observed in the in vitro assays (Supplementary table 1).

As indicated in Figure 1E, luteolin inhibits p300 KAT activity with an $\mathrm{IC}_{50}$ of $7 \mu \mathrm{M}$ but had minimal effect on PCAF even at $20 \mu \mathrm{M}$ concentration. To elucidate the mechanism of inhibition of p300 activity by luteolin, kinetic analysis for the enzyme inhibition was performed. Luteolin inhibits p300 activity in competitive mode with acetyl-coA binding site, whereas it was observed to have characteristics of mixed inhibition with a predominance of competitive binding to the histone binding site (Supplementary figure 1).

These findings clearly indicate that luteolin is a potent acetyltransferase inhibitor with preferential specificity towards p300.

\section{Luteolin inhibits tumour progression by inhibiting histone acetylation in oral cancer cells and tumour xenograft}

To determine the physiological role for this inhibitor, KB cells which exhibit hyperacetylation were treated with luteolin. The acetylation inhibition was observed at low micromolar concentrations $(5 \mu \mathrm{M})$ in the oral cancer cell line after 6 hours of treatment, lower than the observed $\mathrm{IC}_{50}$ from in vitro assay. A decrease in histone $\mathrm{H} 3$ acetylation (H3K9 and H3K14) was observed upon luteolin treatment. At $10 \mu \mathrm{M}$ concentration, an almost complete inhibition of these marks could be observed
(Figure 2A, Lane 4). However, acetylation of histone H4 was relatively less inhibited and histone methylation was unaffected. These results show that luteolin is a potent inhibitor of KAT activity even in the cellular system at low concentration. Hyperacetylation of histones and nonhistone proteins are associated with the progression of oral and liver cancer $[3,15,16]$. Inhibitors of KATs have been implicated as one of the possible epigenetic therapeutics [1]. We decided to investigate the effect of luteolin on two important aspects of tumor progression; cell migration and cell proliferation. It was observed that treatment of luteolin to the UPCI:SCC029B oral cancer cells significantly reduced the wound healing ability in a dose dependent manner (Figure 2B). We also analyzed the effect of luteolin on cell cycle distribution in HNSCC cells and observed that after $24 \mathrm{~h}$ treatment with $25 \mu \mathrm{M}$ luteolin, increased accumulation of cells were observed in $\mathrm{S}$ phase, which is indicative of cell cycle arrest. On the contrary, upon treatment with $25 \mu \mathrm{M}$ luteolin for $48 \mathrm{~h}$, around $16 \%$ of the cell population had accumulated in sub-G1 phase, which is indicative of apoptosis (Figure 2C). Taken together, these data suggest that luteolin acts as an anti-proliferative agent in oral squamous cancer cells in culture. In order to see if the same effect of luteolin was also observed in vivo, we analyzed whether luteolin can inhibit the growth of CAL27 xenografts in nude mice. We found that luteolin treatment $(100 \mathrm{mg} / \mathrm{kg}$ body weight) administered intraperitoneally (i.p.) for 4 weeks, significantly suppressed the tumour growth in vivo following 4 weeks of treatment (Figure $3 \mathrm{~A}$ and 3B). No significant change in body weight of luteolin treated mice was observed during the treatment, thereby indicating that luteolin is apparently non-toxic (Figure 3B, right panel). The alteration of histone acetylation levels was determined by performing immunohistochemical analysis of the xenografted mice tumours. Luteolin treated mice tumours showed decreased levels of H3K9 and K14 acetylation (Figure 3C) thus implicating its KAT inhibitory activity in the tumour tissue. Luteolin inhibited H3 acetylation more potently than $\mathrm{H} 4$ acetylation (Figure $3 \mathrm{C}$ ) which is in accordance with the inhibition pattern from KB cells. The tumour samples also showed decreased levels of proliferation marker Ki67 in the luteolin treated mice. Reduced levels of Ki67 in the tumour sample support the anti-proliferation and anti-tumour activity of luteolin.

\section{Luteolin alters global mRNA and miRNA expression}

Since histone acetylation modulates gene expression, we investigated the effect of acetylation directly upon inhibition of p300 KAT activity in CAL27 cells. An equal number of genes were seen to be up- and downregulated upon luteolin treatment (Figure 4A). Upon closer inspection of the genes, genes like interleukin-6 
A

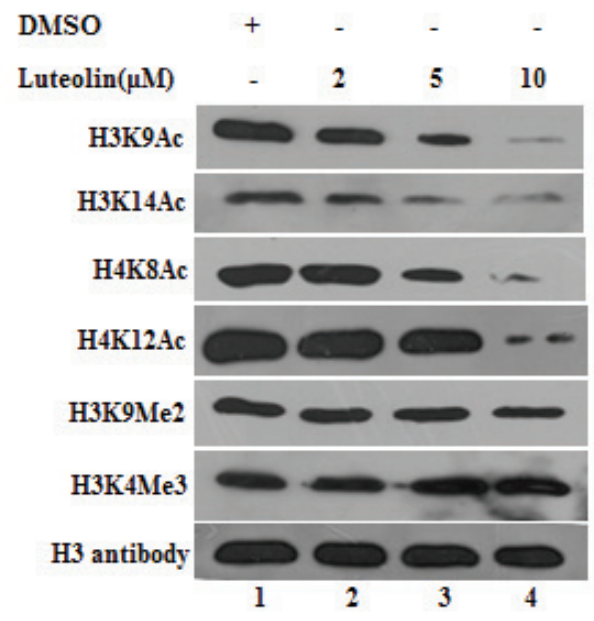

C

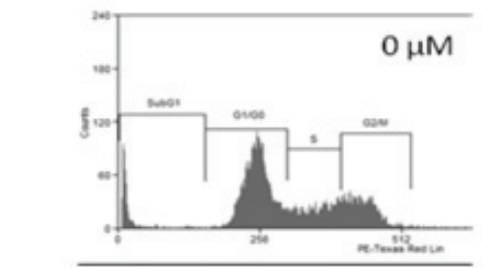

$0 \mu \mathrm{M}(24 \mathrm{~h})$

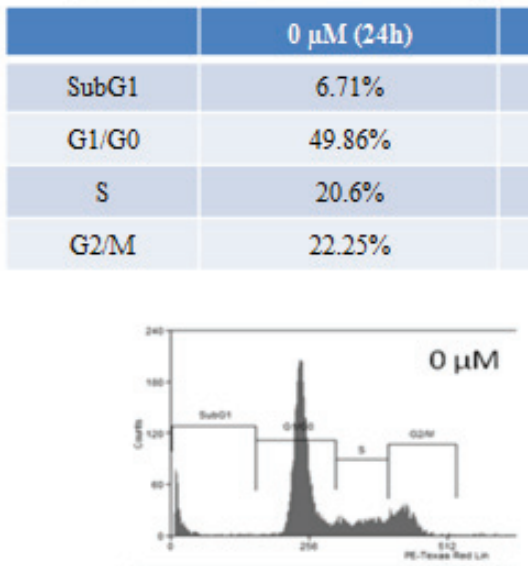

\begin{tabular}{|c|r|}
\hline & $0 \mu \mathrm{M}(\mathbf{4} \mathrm{h})$ \\
\hline SubG1 & $6.72 \%$ \\
\hline $\mathrm{G} 1 / \mathrm{G} 0$ & $62.13 \%$ \\
\hline $\mathrm{S}$ & $15.35 \%$ \\
\hline $\mathrm{G} 2 \mathrm{M}$ & $15.24 \%$ \\
\hline
\end{tabular}

B
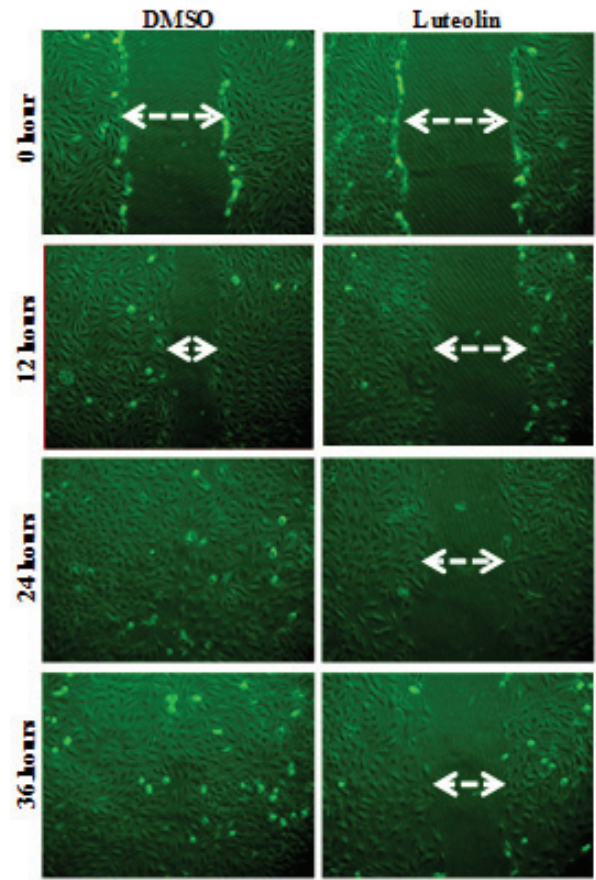

$24 \mathrm{~h}$
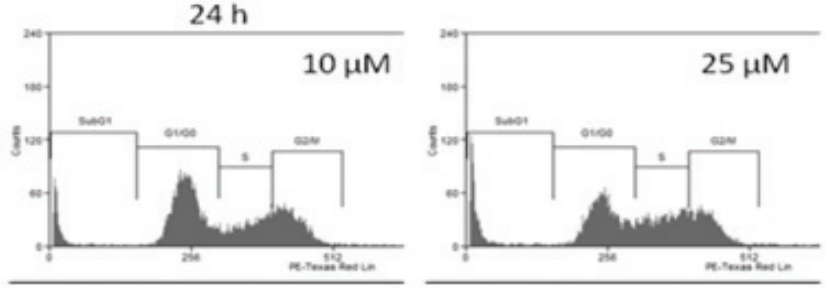

$10 \mu \mathrm{M}$ (24h)

$25 \mu \mathrm{M}(24 \mathrm{~h})$

$6.82 \%$

$11.94 \%$

$45.97 \%$

$35.95 \%$

$21.77 \%$

$28.28 \%$

$24.69 \%$

$22.56 \%$

$48 \mathrm{~h}$
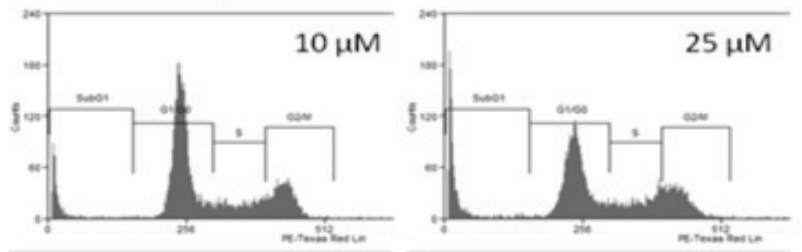

$10 \mu \mathrm{M}(48 \mathrm{~h})$

$25 \mu \mathrm{M}(48 \mathrm{~h})$

$7.67 \%$

$15.95 \%$

$56.35 \%$

$46.08 \%$

$15.61 \%$

$17.56 \%$

$19.96 \%$

$19.99 \%$

Figure 2: Luteolin mediated p300 acetyltransferase inhibition influences cell migration and cell proliferation. A. KB cells were treated with luteolin at different concentrations and the status of histone modifications were analysed. Lane 1 represents histones isolated from the solvent control treated cells, whereas lanes 2-4 represent histones isolated from cells treated with 2, 5 and $10 \mu \mathrm{M}$ of luteolin respectively. Histones were probed with different antibodies as indicated, with histone $\mathrm{H} 3$ used as loading control. B. UPCI:SCC029B oral cancer cells with wounds of constant diameter were treated with $\mathrm{DMSO} /$ luteolin $(10 \mu \mathrm{M})$ for $24 \mathrm{hr}$ along with $10 \%$ serum. The wound photographs were taken under phase-contrast microscope. C. CAL27 cells $\left(5 \times 10^{5} / \mathrm{ml}\right)$ were treated with $10 \mu \mathrm{M}$ and $25 \mu \mathrm{M}$ luteolin for 24 and $48 \mathrm{hr}$ respectively, after which the cells were washed, fixed, stained with PI, and analyzed for DNA content by flow cytometry. 
A

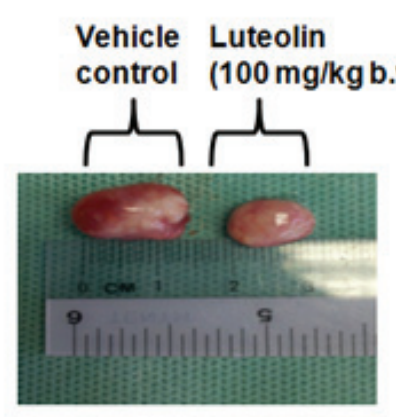

B

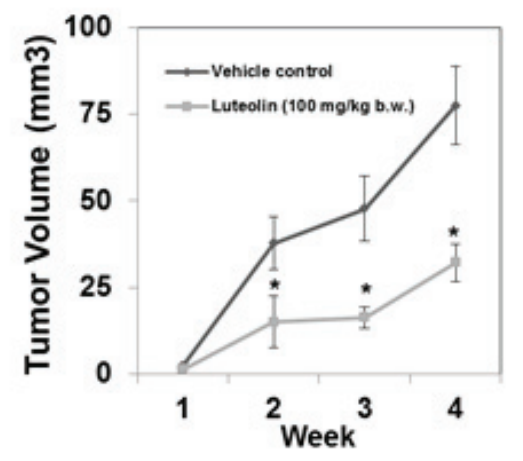

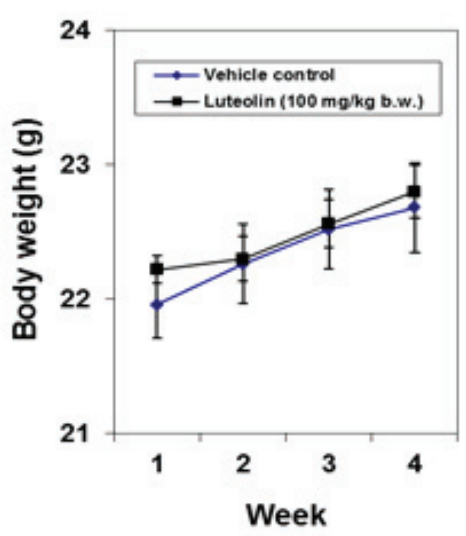

C
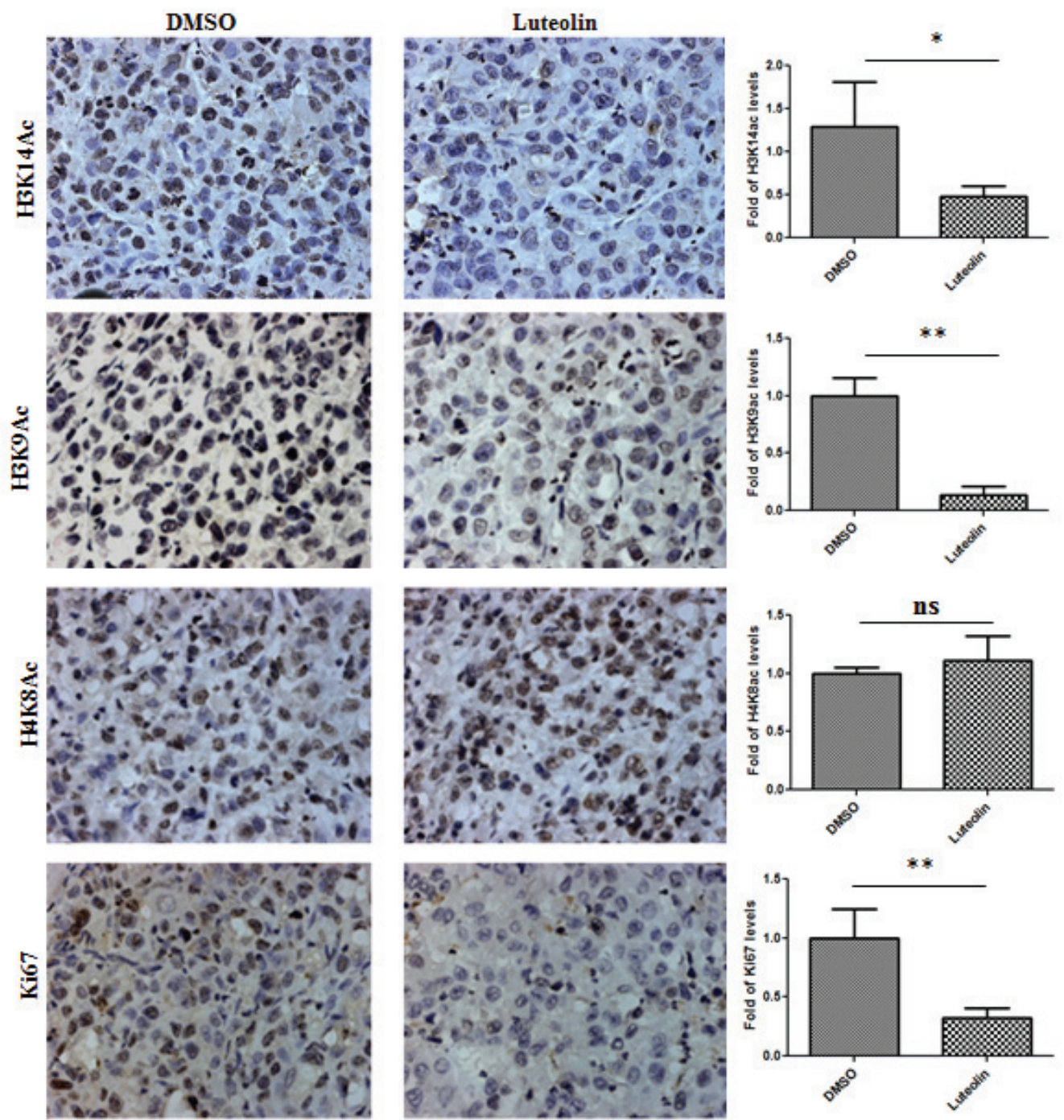

Figure 3: Histone acetylation inhibitor luteolin has in vivo anti-tumor activity. A. Representative image of xenografted tumor of CAL27 cells in athymic balb/c nude male mice. B. Effect of luteolin $(100 \mathrm{mg} / \mathrm{kg}$ b.w. administered i.p. for 4 week, five times per week) on body weight of mice. The data is represented as mean body weight in gm \pm SE. C. IHC images of CAL27 derived tumor samples from mice treated with DMSO or luteolin, stained for H3K14ac, H3K9ac, H4K8ac and proliferation marker Ki67. The quantification depicts the decrease in the level of acetylation as well as proliferation status in the luteolin treated samples. Data is represented as mean tumor volume \pm SE. ${ }^{*} p<0.05$ for control group versus luteolin treatment group at the end of 4 weeks treatment. 
(IL6), which are upregulated in other cancers [17-19] were seen to be downregulated upon luteolin treatment (Figure 4B). Also, genes like E2F2 which control the cell cycle $[20,21]$ and DOK2, the downregulation of which has been observed to worsen prognosis in multiple cancers [22-24], were upregulated (Figure 4B). These changes in the gene expression pattern suggested that luteolin causes changes in gene expression patterns favourable to

\section{A}

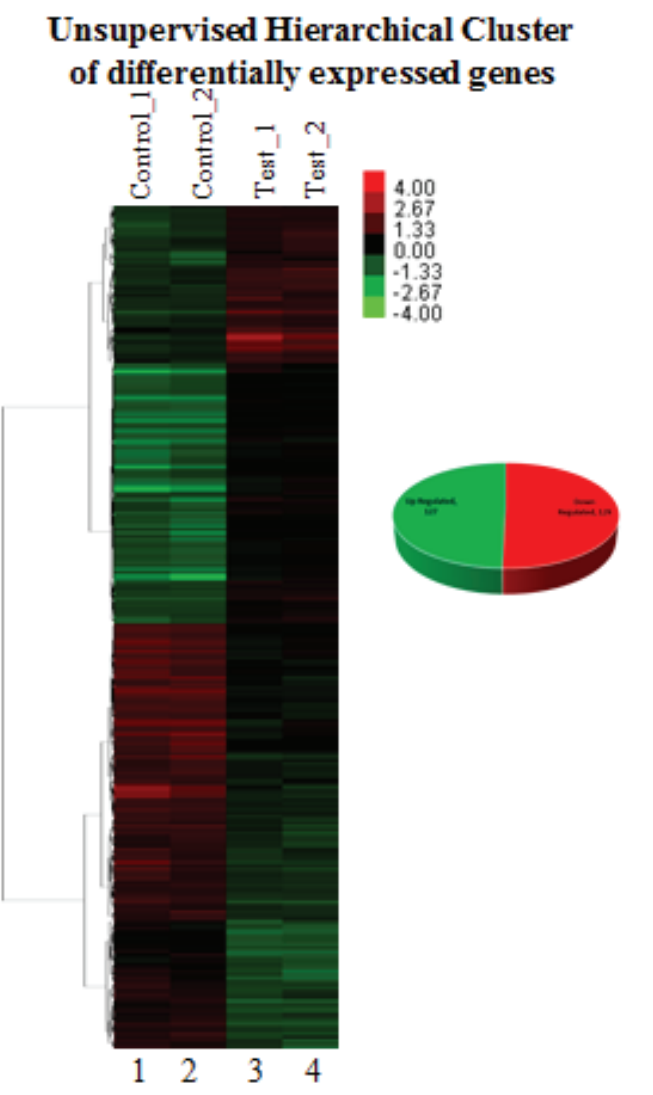

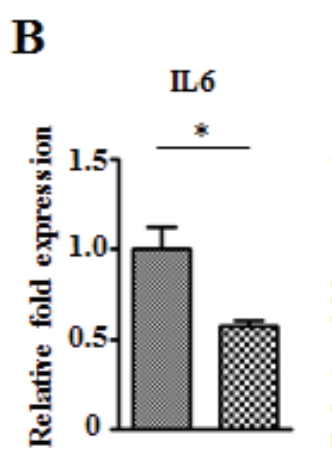
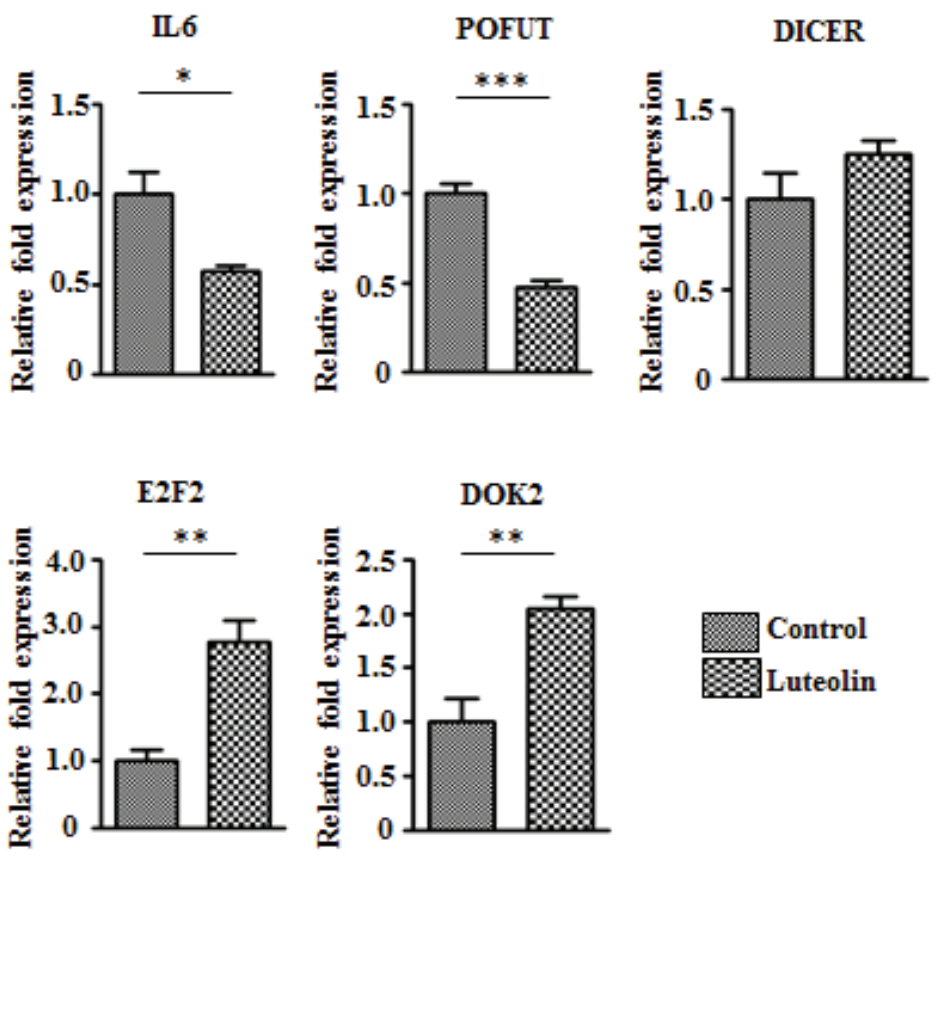

C

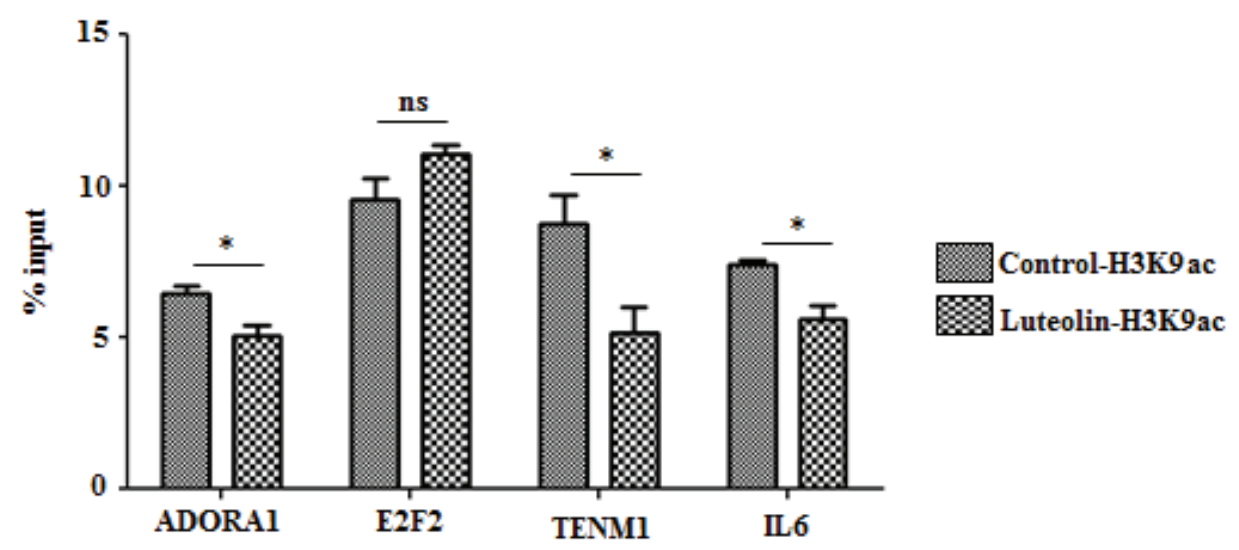

Figure 4: Luteolin mediated p300 acetyltransferase inhibition leads to an alteration in gene expression profile. A. RNA from CAL27 cells treated with $10 \mu \mathrm{M}$ of luteolin was subjected to whole genome microarray analysis to determine the changes in the gene expression profile. Heat map depicting the differentially expressed genes ( 2 fold and above with a $p$ Value of $<0.05$ ) upon luteolin treatment (lanes 3 and 4) in comparison to control samples (lanes 1 and 2), in which equal number of genes was up- and downregulated. B. qPCR validation of representative differentially expressed genes closely related to tumor progression. $\left(n=3 ;{ }^{*}, p<0.05 ; * *, p<0.01\right.$, $\left.{ }^{* * *}, p<0.001\right)$. C. Chromatin immunoprecipitation followed by qPCR performed with UPCI:SCC029B oral carcinoma cells treated with $10 \mu \mathrm{M}$ luteolin for 8 hours. Quantification of immunoprecipitated DNA is represented relative to the input DNA. $\left(n=3 ;{ }^{*} p<0.05\right.$; ns, not significant). H3K9ac was normalized against $\mathrm{H} 3$ levels in the selected promoters in control DMSO treated and luteolin treated cells. 
inhibition of cancer progression. In order to understand the direct effect of luteolin mediated inhibition of histone acetylation on gene expression, we performed a chromatin immunoprecipitation analysis for $\mathrm{H} 3 \mathrm{~K} 9$ acetylation on gene promoters using UPCI:SCC029B oral cancer cell line treated with $10 \mu \mathrm{M}$ luteolin. Interestingly, on the promoters of factors like IL6 and ADORA1, which are upregulated in cancers and are associated with poor prognosis, histone acetylation was found to be significantly repressed upon luteolin treatment (Figure 4C). In addition, luteolin treatment could significantly reduce the $\mathrm{H} 3 \mathrm{~K} 9$ acetylation on the promoter of TENM1, which is observed to be upregulated in several cancers. However, histone acetylation on the promoter of tumor suppressor E2F2 showed no significant change in response to luteolin. Thus, the inhibitory potential of luteolin could directly be correlated with reduced acetylation on gene promoters, especially in case of tumor promoting factors.

Interestingly, we noted that DICER showed an upregulation of expression upon luteolin treatment (Figure 4B). This suggested possible changes in the miRNA profile in addition to the gene expression changes that were observed. Indeed, we observed that treatment of luteolin in KB cells triggered both up-regulation as well as down-regulation of various sets of miRNA (Figure $5 \mathrm{~A}$ ). About 40 miRNAs including let $7 \mathrm{c}$ showed more than 2-fold differential expression in $10 \mu \mathrm{M}$ luteolin treated cells over DMSO treated cells (Figure 5B). The alteration of miRNA expression by luteolin was also validated in the UPCI:SCC029B oral squamous cell carcinoma cells. Treatment of luteolin induced upregulation of miR221, miR98 and let7c as well as downregulated expression of miR135a, miR1281 and miR377 were down-regulated as also validated by qRT-PCR analysis (Figure 5C). A large percentage of the dysregulated genes and miRNAs belonged to the categories of gene expression, signal transduction and cell proliferation, which are the principal processes controlling cancer progression (Figure 5D).
A

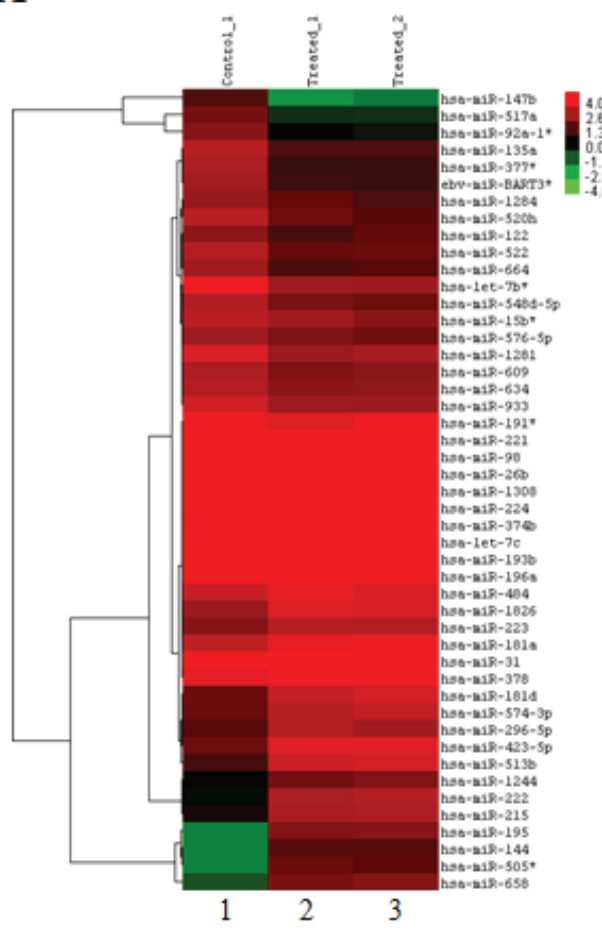

C

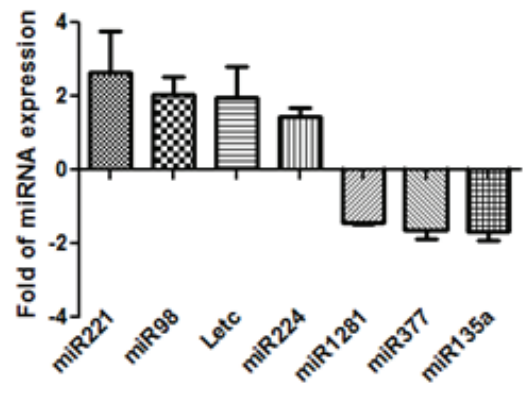

B
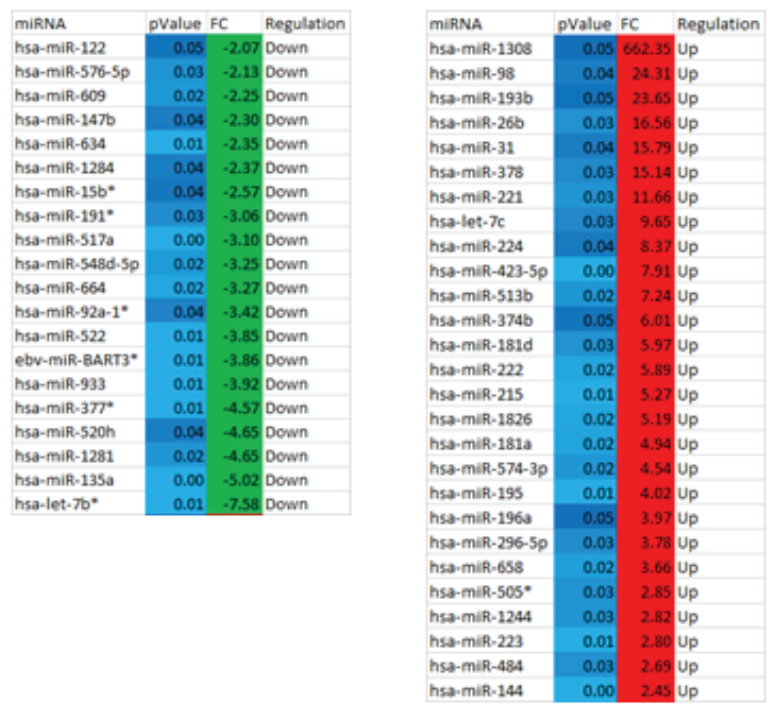

D
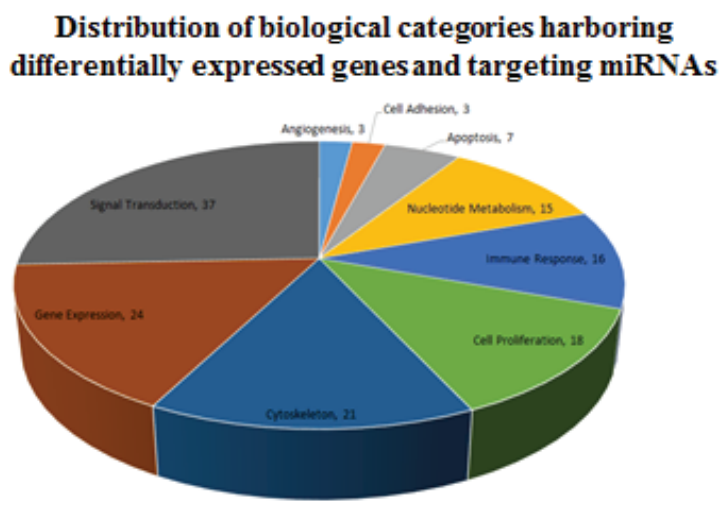


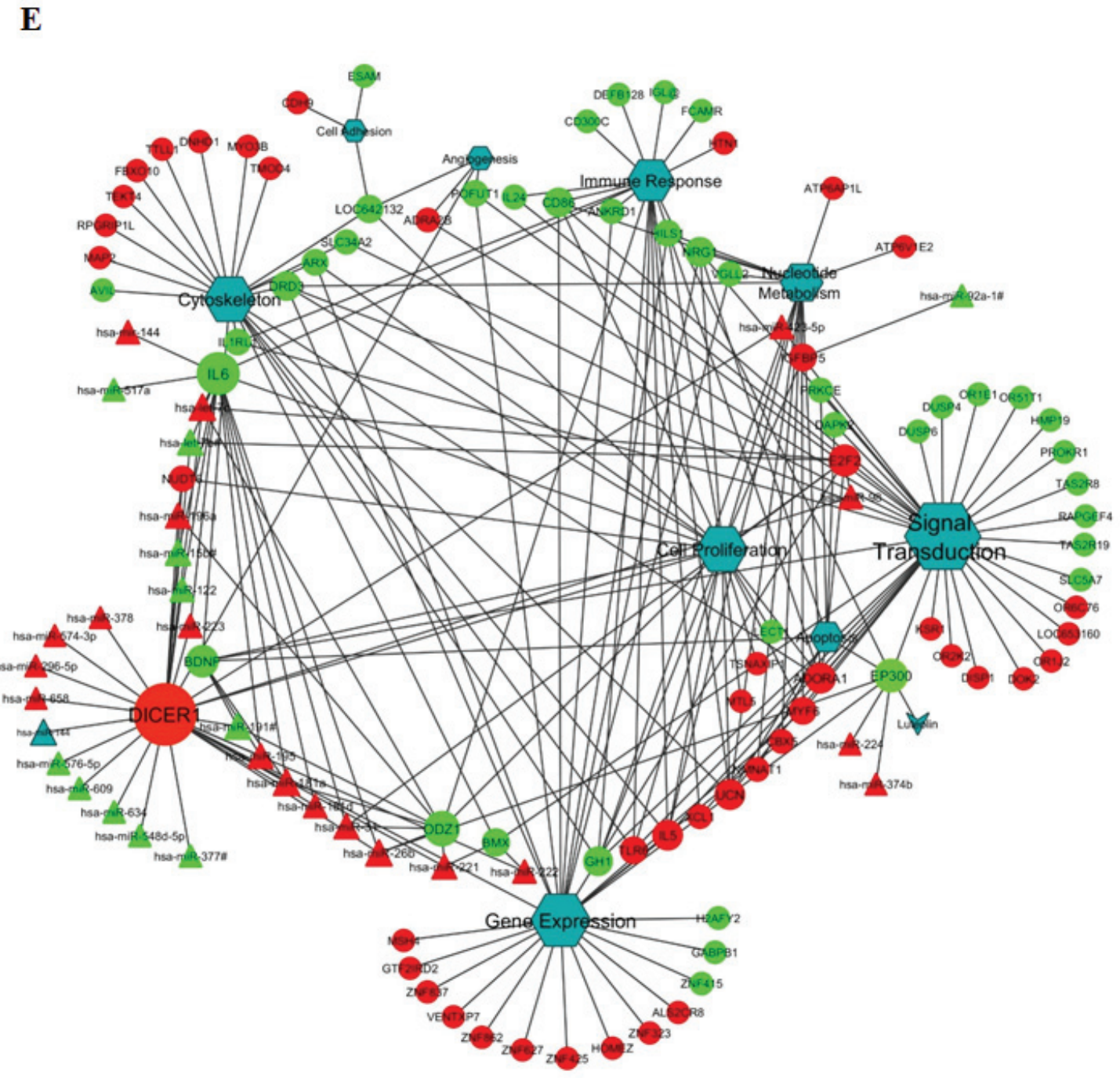

Figure 5: Luteolin mediated p300 acetyltransferase inhibition influences miRNA network correlating to tumor suppression. A. RNA from KB cells treated with $10 \mu \mathrm{M}$ of luteolin was subjected to whole genome miRNA microarray analysis to determine the changes in the miRNA profile. Heat map depicting the differentially expressed miRNA ( 2 fold and above with a $p$ Value of $<0.05$ ) upon luteolin treatment (lanes 2 and 3 ) in comparison to untreated samples (lane 1). B. . List of induced and repressed miRNA upon luteolin treatment with fold change of 2 and above with a $p$ Value of $<0.05$ (calculated by Student T-test. C. qPCR validation of the selected differentially expressed miRNA upon treatment with $10 \mu \mathrm{M}$ luteolin for $6 \mathrm{hrs}$ in UPCI: SCC029B cells. D. . Distribution of biological categories harboring differentially expressed genes and targeting miRNAs. E. miRNA perturbation and gene network upon luteolin treatment. The presence of cell proliferation in the middle of the network indicates significant dysregulation of genes closely associated with cancer. Also, the mapping of DICER as an important node suggests that the activity of luteolin is at multiple levels: at the level of gene expression, miRNA expression and miRNA processing.

Interestingly, luteolin has been shown to downregulate cell cycle associated genes in several cancer cell models and partly has been attributed to its effect on the phospho-signaling cascade albeit in higher concentrations than reported here [25]. Hence, in order to visualize the interactions that are associated with p300 acetylation inhibition by luteolin with gene and miRNA perturbations, we modelled a miRNA and gene network map. This analysis clearly portrays a complex regulatory network with various genes and miRNAs centered around cell proliferation and signal transduction (Figure 5E). As predicted earlier, DICER forms an important node, indicating that luteolin influences miRNA expression and miRNA processing in addition to the other effect on other pathways. Also, factors like IL6, ADORA1, ODZ1 and E2F2 which have been validated by H3K9ac ChIP, formed important nodes in this network.

Taking together all these observations, it is clear that luteolin treatment leads to an overall perturbation of gene expression and miRNA profile favouring a tumor suppression effect, thereby signifying the protective role of the dietary flavonoid luteolin as an anticancer agent. 


\section{DISCUSSION}

Crude extract of pomegranate (PCE) has been considered as a therapeutic agent for several decades and its medicinal values have been observed as antimicrobial, anti-parasitic, anti-viral and anti-cancer effects. Ellagic acid or TBBD isolated from PCE exerts PRMT4/CARM1 inhibitory effect which specifically translates to histone H3R17 methylation inhibition without affecting H3R26 methylation [6]. In our present study, we observed that a few components of PCE also inhibit lysine acetyltransferase activity of p300. A few of these, such as gallic acid and EGCG have already been reported to have epigenetic modulatory effect [26, 27]. A significant observation from our study was that an important dietary flavonoid, luteolin was found to be a potent p300 acetyltransferase inhibitor. Apart from the reported EGCG and luteolin (identified in our present study), no other component exhibited any significant p300 inhibition. The flavanoids and luteolin are widely acclaimed for their antioxidant properties and their overall protective effect. The fact that they are present in edible fruits and vegetables, implicates their biological utility. We also identified that the structurally related apigenin does not inhibit p300 activity which could be ascribed to their differential binding on to the p300 HAT domain. A significant observation is that when apigenin is tested ex vivo on tissues, it is known to get converted to luteolin and then metabolised by the system [28]. All these studies suggest that luteolin is a biologically useful molecule and it can be metabolised without any accumulation and downstream side effects. Several theories have been presented to elucidate the mechanism behind the anticancer activity of luteolin. Recently, it was reported that luteolin potentiates histone deacetylase inhibition activity [29] whereas another report suggests that it inhibits kinase activity of aurora B [30] and thereby blocks cancer cell proliferation. However, it inhibits HDACs at a very high concentration $(100 \mu \mathrm{M})$ as compared to its kinase and acetylation inhibitory concentration $(5-10 \mu \mathrm{M})$. Histone hyperacetylation is a common characteristic of oral cancers and thus the KAT inhibitors have proved to be a promising therapeutic agent against it. Luteolin inhibits tumour progression by inhibiting angiogenesis probably by inhibiting acetylation, as p300 acetyltransferase activity is closely related to angiogenesis. Silencing p300/ CBP results in compromised tube formation and inhibits angiogenesis [31]. Several studies on cancer models both as cell lines and tumours have investigated the effect of luteolin on angiogenesis and it has been shown that luteolin downregulates VEGF expression [32]. A major conclusion from our study also supports the antiangiogenic property of luteolin. There is also evidence of luteolin mediated induction of apoptosis in the oral cancer cell line used for the xenograft study as observed by the cell cycle analysis. We show that luteolin inhibits acetylation in cells, as well as in HNSCC xenograft tumor model. Histone acetylation regulates gene expression, and treatment with luteolin resulted in dysregulated expression of important inflammatory cytokines and cell cycle regulatory proteins, this being a direct downstream effect of reduced histone acetylation on these gene promoters. Consistently, gene expression, cell proliferation and immune response formed important nodes when we mapped the gene expression and miRNA expression data as a network. The GO clustering of the altered miRNA clearly implicate an upregulation of tumor suppressive miRNA and a down-regulation of tumorogenic miRNA expression. Although broad spectrum HDACi treatments alter the miRNA expression profile, the direct role of KAT activity in miRNA expression is yet to be elucidated. Significantly, we found that one of the upregulated genes, DICER formed an important node, indicating potential regulation of miRNA maturation, along with changes in expression of miRNAs. Knocking down DICER leads to changes in chromatin signature and hence, affects gene expression, with an increase in histone acetylation and decrease in methylation [33-35]. Hence, the changes in gene and miRNA expression might also be a result of other additional phenomena, apart from the direct effect of luteolin on p300-mediated histone acetylation.

We found that 6 hours treatment of luteolin to KB and SCC029B cells differentially regulates the expression of miRNAs which play crucial roles in angiogenesis and cancer cell proliferation. Incidentally, the pomegranate juice components tested against prostate cancer cells also revealed a similar miRNA alteration profile [36]. However, in this report we have provided a concise miRNA-gene network that is exclusive to luteolin treatment at an IC50 of $7 \mu \mathrm{M}$ concentration in the oral cancer cells. This finding may contribute immensely to our search for a therapeutic agent which is obtained from natural products that may prove to be valuable tool to fight against oral cancer. This study also appropriately connects the alteration of histone acetylation to tumour regression through regulation of gene expression directly and by miRNA regulation.

\section{MATERIALS AND METHODS}

\section{Filter binding assay}

$\mathrm{KAT} / \mathrm{RMT}$ assays were performed as described previously [13] and are described in the supplementary section.

\section{Immunoblotting assay}

$\mathrm{KB}$ cells $\left(1.5 \times 10^{6}\right.$ cells per $60-\mathrm{mm}$ dish $)$ were seeded overnight, and histones were extracted by acid extraction after 6 hours of treatment with increasing 
concentrations of luteolin. Immunoblotting analysis was performed as described elsewhere [13], using polyclonal acetylated histone $\mathrm{H} 3 \mathrm{~K} 9, \mathrm{H} 3 \mathrm{~K} 14, \mathrm{H} 4 \mathrm{~K} 8$, $\mathrm{H} 4 \mathrm{~K} 12, \mathrm{H} 3 \mathrm{~K} 9 \mathrm{me} 2, \mathrm{H} 3 \mathrm{~K} 4 \mathrm{me} 3$ and polyclonal histone $\mathrm{H} 3$ antibodies.

\section{Molecular docking studies}

Crystal structure of p300 KAT domain was extracted from Protein Data Bank code 3BIY. Crystal structure of the luteolin and apigenin was obtained and solved (Bruker X8 APEX). The KAT domain was docked with the structure of luteolin and apigenin to find out their interaction sites on KAT domain.

\section{HNSCC cancer xenograft mouse}

Model was used as described in [37]. Control group was treated with $0.1 \%$ DMSO and treatment group mice received intraperitoneal injection (i.p.) $100 \mathrm{mg} / \mathrm{kg}$ luteolin five times a week for 4 weeks from the date of randomization.

\section{Immunohistochemical analysis of tumor samples}

Was performed as described in [37] and is described in the supplementary section.

\section{Gene expression analysis}

Was performed as described earlier in [6]. Briefly, following treatment with luteolin, total RNA was isolated using TRIzol reagent (Invitrogen). cDNA was synthesized with oligo(dT) (28-mer) (Invitrogen) and Moloney murine leukemia virus reverse transcriptase (Sigma), and expression analysis was carried out using SYBR Green supermix (Kapa) and gene-specific primers.

\section{Microarray and miRNA array}

Were performed using RNA extracted using the Trizol method. The array and the following analysis was performed as described previously [7] and is described in the supplementary section.

\section{miRNA expression analysis}

Invitrogen Ncode VILO cDNA synthesis kit was used to make cDNA from RNA isolated by Trizol method, following the manufacturer's instructions. The cDNA made thus was used for downstream qRT-PCR based profiling.

\section{Wound healing assay}

Was performed as described earlier in Arif $\mathrm{M}$ et al. [3].

\section{Flow cytometric analysis}

To determine the effect of luteolin on the cell cycle, CAL27 cells $(5 \times 105 / \mathrm{ml})$ were seeded in 6-well plate and then treated with to $10 \mu \mathrm{M}$ and $25 \mu \mathrm{M}$ luteolin for 24 and $48 \mathrm{~h}$ respectively. Thereafter cells were trypsinized, washed with PBS, and fixed with $70 \%$ ethanol for $30 \mathrm{~min}$ on ice. Cells were then washed again, resuspended, and stained in PBS containing $10 \mu \mathrm{g} / \mathrm{ml}$ propidium iodide (PI) and $1 \mu \mathrm{g} / \mathrm{ml}$ RNase A for $30 \mathrm{~min}$ at room temperature. Cell distribution across the cell cycle was analyzed with a CyAn ADP flow cytometer (Dako Cytomation).

Chromatin Immunoprecipitation analysis was performed as described in ref 6.

\section{ACKNOWLEDGMENTS}

We acknowledge Prof. Susanne M. Gollin, Department of Human Genetics and the University of Pittsburgh Cancer Institute, University of Pittsburgh, Pittsburgh, PA, for kindly providing the SCC029B cell line. This work was supported by Department of Biotechnology, Govt. of India (Chromatin and Disease: Programme support grant number Grant/BT/01/CEIB/10/ III/01 and Grant/DBT/PR3018/NNT/28/544/2011) and Jawaharlal Nehru Centre for Advanced Scientific Research, Bangalore, India. TKK is the recipient of Sir J.C. Bose national fellowship, Department of Science and Technology, Govt. of India. This work was supported by NUHS Bench-to-Bedside grant to GS. The Deanship of Scientific Research, College of Science Research Centre, King Saud University, Kingdom of Saudi Arabia also supported the work. This work was also supported by grant from National Medical Research Council to GS. AS is a CSIR-SRF.

\section{CONFLICTS OF INTEREST}

The authors declare no conflict of interest.

\section{REFERENCES}

1. Selvi BR, Mohankrishna DV, Ostwal YB and Kundu TK. Small molecule modulators of histone acetylation and methylation: a disease perspective. Biochim Biophys Acta. 2010; 1799:810-828.

2. Mantelingu K, Reddy BA, Swaminathan V, Kishore AH, Siddappa NB, Kumar GV, Nagashankar G, Natesh N, Roy S, Sadhale PP, Ranga U, Narayana C and Kundu 
TK. Specific inhibition of p300-HAT alters global gene expression and represses HIV replication. Chem Biol. 2007; 14:645-657.

3. Arif M, Vedamurthy BM, Choudhari R, Ostwal YB, Mantelingu K, Kodaganur GS and Kundu TK. Nitric oxidemediated histone hyperacetylation in oral cancer: target for a water-soluble HAT inhibitor, CTK7A. Chem Biol. 2010; 17:903-913.

4. Lau OD, Kundu TK, Soccio RE, Ait-Si-Ali S, Khalil EM, Vassilev A, Wolffe AP, Nakatani Y, Roeder RG and Cole PA. HATs off: selective synthetic inhibitors of the histone acetyltransferases p300 and PCAF. Mol Cell. 2000; 5:589595.

5. Bowers EM, Yan G, Mukherjee C, Orry A, Wang L, Holbert MA, Crump NT, Hazzalin CA, Liszczak G, Yuan H, Larocca C, Saldanha SA, Abagyan R, Sun Y, Meyers DJ, Marmorstein R, et al. Virtual ligand screening of the p300/ CBP histone acetyltransferase: identification of a selective small molecule inhibitor. Chem Biol. 2010; 17:471-482.

6. Selvi BR, Batta K, Kishore AH, Mantelingu K, Varier RA, Balasubramanyam K, Pradhan SK, Dasgupta D, Sriram S, Agrawal S and Kundu TK. Identification of a novel inhibitor of coactivator-associated arginine methyltransferase 1 (CARM1)-mediated methylation of histone H3 Arg-17. J Biol Chem. 2010; 285:7143-7152.

7. Selvi BR, Swaminathan A, Maheshwari U, Nagabhushana A, Mishra RK and Kundu TK. CARM1 regulates astroglial lineage through transcriptional regulation of Nanog and posttranscriptional regulation by miR92a. Mol Biol Cell. 2014; 26:316-326.

8. Romagnolo DF and Selmin OI. Flavonoids and cancer prevention: a review of the evidence. J Nutr Gerontol Geriatr. 2012; 31:206-238.

9. Jones QR, Warford J, Rupasinghe HP and Robertson GS. Target-based selection of flavonoids for neurodegenerative disorders. Trends Pharmacol Sci. 2012; 33:602-610.

10. Ebrahimi A and Schluesener H. Natural polyphenols against neurodegenerative disorders: potentials and pitfalls. Ageing Res Rev. 2012; 11:329-345.

11. Brunetti C, Di Ferdinando M, Fini A, Pollastri S and Tattini M. Flavonoids as antioxidants and developmental regulators: relative significance in plants and humans. Int $\mathrm{J}$ Mol Sci. 2013; 14:3540-3555.

12. Kim BH, Choi JS, Yi EH, Lee JK, Won C, Ye SK and Kim MH. Relative antioxidant activities of quercetin and its structurally related substances and their effects on NFkappaB/CRE/AP-1 signaling in murine macrophages. Mol Cells. 2013; 35:410-420.

13. Ravindra KC, Selvi BR, Arif M, Reddy BA, Thanuja GR, Agrawal S, Pradhan SK, Nagashayana N, Dasgupta $\mathrm{D}$ and Kundu TK. Inhibition of lysine acetyltransferase KAT3B/p300 activity by a naturally occurring hydroxynaphthoquinone, plumbagin. J Biol Chem. 2009; 284:24453-24464.
14. Liu X, Wang L, Zhao K, Thompson PR, Hwang Y, Marmorstein $\mathrm{R}$ and Cole PA. The structural basis of protein acetylation by the p300/CBP transcriptional coactivator. Nature. 2008; 451:846-850.

15. Lee CW, Wong LL, Tse EY, Liu HF, Leong VY, Lee JM, Hardie DG, Ng IO and Ching YP. AMPK promotes p53 acetylation via phosphorylation and inactivation of SIRT1 in liver cancer cells. Cancer Res. 2012; 72:4394-4404.

16. Fernandez-Marcos PJ, Jeninga EH, Canto C, Harach T, de Boer VC, Andreux P, Moullan N, Pirinen E, Yamamoto H, Houten SM, Schoonjans K and Auwerx J. Muscle or liver-specific Sirt3 deficiency induces hyperacetylation of mitochondrial proteins without affecting global metabolic homeostasis. Sci Rep. 2012; 2:425.

17. Schafer ZT and Brugge JS. IL-6 involvement in epithelial cancers. J Clin Invest. 2007; 117:3660-3663.

18. Nguyen DP, Li J and Tewari AK. Inflammation and prostate cancer: the role of interleukin 6 (IL-6). BJU Int. 2014; 113:986-992.

19. Waldner MJ, Foersch S and Neurath MF. Interleukin-6-a key regulator of colorectal cancer development. Int J Biol Sci. 2012; 8:1248-1253.

20. Pusapati RV, Weaks RL, Rounbehler RJ, McArthur MJ and Johnson DG. E2F2 suppresses Myc-induced proliferation and tumorigenesis. Mol Carcinog. 2010; 49:152-156.

21. Opavsky R, Tsai SY, Guimond M, Arora A, Opavska J, Becknell B, Kaufmann M, Walton NA, Stephens JA, Fernandez SA, Muthusamy N, Felsher DW, Porcu P, Caligiuri MA and Leone G. Specific tumor suppressor function for E2F2 in Myc-induced T cell lymphomagenesis. Proc Natl Acad Sci U S A. 2007; 104:15400-15405.

22. Wen X, Zhou M, Guo Y, Zhu Y, Li H, Zhang L, Yu L, Wang $X$ and Peng $X$. Expression and significance of DOK2 in colorectal cancer. Oncol Lett. 2015; 9:241-244.

23. Lum E, Vigliotti M, Banerjee N, Cutter N, Wrzeszczynski KO, Khan S, Kamalakaran S, Levine DA, Dimitrova N and Lucito R. Loss of DOK2 induces carboplatin resistance in ovarian cancer via suppression of apoptosis. Gynecol Oncol. 2013; 130:369-376.

24. Berger AH, Niki M, Morotti A, Taylor BS, Socci ND, Viale A, Brennan C, Szoke J, Motoi N, Rothman PB, TeruyaFeldstein J, Gerald WL, Ladanyi M and Pandolfi PP. Identification of DOK genes as lung tumor suppressors. Nat Genet. 2010; 42:216-223.

25. Lopez-Lazaro M. Distribution and biological activities of the flavonoid luteolin. Mini Rev Med Chem. 2009; 9:31-59.

26. Kim MJ, Seong AR, Yoo JY, Jin CH, Lee YH, Kim YJ, Lee J, Jun WJ and Yoon HG. Gallic acid, a histone acetyltransferase inhibitor, suppresses beta-amyloid neurotoxicity by inhibiting microglial-mediated neuroinflammation. Mol Nutr Food Res. 2011; 55:17981808.

27. Choi KC, Jung MG, Lee YH, Yoon JC, Kwon SH, Kang HB, Kim MJ, Cha JH, Kim YJ, Jun WJ, Lee JM and Yoon 
HG. Epigallocatechin-3-gallate, a histone acetyltransferase inhibitor, inhibits EBV-induced B lymphocyte transformation via suppression of RelA acetylation. Cancer Res. 2009; 69:583-592.

28. Gradolatto A, Canivenc-Lavier MC, Basly JP, Siess MH and Teyssier C. Metabolism of apigenin by rat liver phase I and phase ii enzymes and by isolated perfused rat liver. Drug Metab Dispos. 2004; 32:58-65.

29. Attoub S, Hassan AH, Vanhoecke B, Iratni R, Takahashi T, Gaben AM, Bracke M, Awad S, John A, Kamalboor HA, Al Sultan MA, Arafat K, Gespach C and Petroianu G. Inhibition of cell survival, invasion, tumor growth and histone deacetylase activity by the dietary flavonoid luteolin in human epithelioid cancer cells. Eur J Pharmacol. 2011; 651:18-25.

30. Xie F, Lang Q, Zhou M, Zhang H, Zhang Z, Zhang Y, Wan B, Huang Q and Yu L. The dietary flavonoid luteolin inhibits Aurora B kinase activity and blocks proliferation of cancer cells. Eur J Pharm Sci. 2012; 46:388-396.

31. Aikawa Y, Nguyen LA, Isono K, Takakura N, Tagata Y, Schmitz ML, Koseki H and Kitabayashi I. Roles of HIPK1 and HIPK2 in AML1- and p300-dependent transcription, hematopoiesis and blood vessel formation. EMBO J. 2006; 25:3955-3965.

32. Pratheeshkumar P, Son YO, Budhraja A, Wang X, Ding S, Wang L, Hitron A, Lee JC, Kim D, Divya SP, Chen G, Zhang Z, Luo J and Shi X. Luteolin inhibits human prostate tumor growth by suppressing vascular endothelial growth factor receptor 2-mediated angiogenesis. PLoS One. 2012; 7:e52279.

33. Haussecker D and Proudfoot NJ. Dicer-dependent turnover of intergenic transcripts from the human beta-globin gene cluster. Mol Cell Biol. 2005; 25:9724-9733.

34. Giles KE, Ghirlando R and Felsenfeld G. Maintenance of a constitutive heterochromatin domain in vertebrates by a Dicer-dependent mechanism. Nat Cell Biol. 2010; 12:9499; sup pp 91-96.

35. Tang KF, Wang Y, Wang P, Chen M, Chen Y, Hu HD, Hu P, Wang B, Yang W and Ren H. Upregulation of PHLDA2 in Dicer knockdown HEK293 cells. Biochim Biophys Acta. 2007; 1770:820-825.

36. Wang L, Ho J, Glackin C and Martins-Green M. Specific pomegranate juice components as potential inhibitors of prostate cancer metastasis. Transl Oncol. 2012; 5:344-355.

37. Li F, Shanmugam MK, Chen L, Chatterjee S, Basha J, Kumar AP, Kundu TK and Sethi G. Garcinol, a polyisoprenylated benzophenone modulates multiple proinflammatory signaling cascades leading to the suppression of growth and survival of head and neck carcinoma. Cancer Prev Res (Phila). 2013; 68:43-854. 